\title{
A ESCRITA FEMININA EM FAZES-ME FALTA: CORPO MORTO, CORPUS DESCONTRUÍDO
}

\author{
Diana Navas ${ }^{1}$ \\ Telma Regina Ventura ${ }^{2}$
}

RESUMO: O presente estudo objetiva apresentar como na obra Fažes-me falta, de Inês Pedrosa, uma das mais significativas vozes da literatura contemporânea portuguesa, a autora, valendo-se da escrita feminina, empreende uma crítica à condição da mulher em nosso atual contexto ao mesmo tempo em que aproxima essa condição ao processo de desconstrução da tessitura do romance. Ou seja, almeja-se observar a fusão que se estabelece entre o corpo da personagem feminina e o corpus narrativo em seu processo de (des)construção. Recorrendo aos conceitos de escrita feminina, a pesquisa evidencia-nos uma narrativa questionadora do paradigma oficial e a configuração de uma mulher-narrativa, marcada pela incompletude e fragmentação.

Palavras-chave: Escrita Feminina; Inês Pedrosa; descontrução; mulher-narrativa.

\section{THE FEMININE WRITING IN FAZES-ME FALTA: DEAD BODY, DECONSTRUCTED CORPUS}

\begin{abstract}
The present study aims to present how in the work Fazes-me falta, written by Inês Pedrosa, one of the most significative voices of the Contemporary Portuguese Literature, the author, making use of the feminine writing, undertakes a critique of the condition of women in our present context while bringing this condition closer to the process of deconstruction of the novel. In other words, it aims to observe the fusion that is established between the body of the female character and the narrative corpus in its process of (de)construction. Exploratory and bibliographical, and making use of the feminine writing, the research reveals a questioning narrative of the official paradigm and the configuration of a woman-narrative, marked by incompleteness and fragmentation.
\end{abstract}

Keywords: Feminine Writing; Inês Pedrosa; deconstruction; woman-narrative.

\section{Aspectos da narrativa desconstrucionista na Literatura Portuguesa Contemporânea}

A Revolução dos Cravos, ocorrida em 25 de abril de 1974, demarcou o fim da ditadura salazarista que há décadas oprimia Portugal. Mesmo que com um nome lírico, essa revolução se consolidou após uma violenta luta contra a repressão que tentou, de todas as maneiras, abafar os protestos e reivindicações da população. Os movimentos democráticos, fomentados particularmente pelo movimento juvenil e pelos intelectuais, foram decisivos

\footnotetext{
${ }^{1}$ Pós-doutora pela Universidade de Aveiro e doutora em Literatura Portuguesa pela Universidade de São Paulo. Atua como professora no Programa de Estudos Pós-Graduados da Pontifícia Universidade Católica de São Paulo. Suas pesquisas concentram-se nas tendências da literatura portuguesa contemporânea, mais especificamente, nos romances de António Lobo Antunes. Dentre suas produções, destacam-se: Narcisismo discursivo e metaficção - Lobo Antunes e a revolução do romance (2009) e Figurações da escrita (2013).

2 Mestranda em Literatura e Crítica Literára pela Pontifícia Universidade Católica de São Paulo (PUC/SP), cuja dissertação intitula-se: "Narradoras e Narrativas: A escrita intertextual de Inês Pedrosa".
} 
para as transformações desse processo histórico que fez frente à ditadura. Os artistas tiveram uma participação essencial nesse período por meio da revolução na literatura, e são denominados por Simões de 'Geração de Abril'. A teórica traça um estreito paralelo entre a produção literária e a revolução político-social no que tange à denúncia à opressão e à luta contra a ditadura, consequente conquista da democracia e busca por novas identidades: "A revolução portuguesa passa da ditadura para a democracia em paralelo com a revolução que acontece no processo da comunicação literária, a qual ultrapassa os recursos do silêncio, criando um novo discurso e novas formas de comunicação" (SIMÕES, 1997, p.213).

A década de 1960 foi crucial para todo o movimento histórico que culminou na Revolução dos Cravos, visto que gestou a consciência libertária da ação antiditatorial. O silêncio impingido à população pelo salazarismo transfigurou-se em um intenso processo de criação de um discurso no qual a economia de palavras tornou-se um gesto de protesto. A contenção de palavras e as metáforas, utilizadas como recursos estilísticos, visavam registrar e também questionar a História, incluindo a situação de subordinação e opressão da mulher no contexto português do período. Maria Isabel Barreno, Maria Velho da Costa e Maria Teresa Horta, utilizando-se da palavra literária na luta contra os valores patriarcais, publicaram, em 1972, Novas cartas portuguesas, o que lhes valeu uma punição pela ditadura de Marcelo Caetano, que considerou o livro imoral e pornográfico. As autoras, além de lutarem pela própria liberdade de expressão, expuseram o desejo da mulher de escrever sua própria história.

A geração literária que se formou a partir de então, embora herdeiros distantes do neorrealismo, preocupou-se prioritariamente com o nível discursivo, o que, entretanto, já era uma tendência da época: "A linguagem literária evidencia uma tendência para o experimentalismo e a fragmentação. O papel do artista na sociedade deveria ser o de luta sutil” (SIMÕES, 1997, p.211). Destarte, a marca decisiva do discurso literário português do período foi o estilo experimentalista, mesmo que marcada pelo caráter documental.

Certamente, após décadas de repressão fascista, o povo português vivenciava as marcas da própria crise de identidade, às quais se somaram as questões da colonização e dos retornados. Tais fatos constituíram, pois, a temática da escrita de muitos romancistas e poetas que, conscientes dessa crise, decidiram escrever uma nova História, parodiando a oficial. A reconstrução histórico-social de Portugal é assim idealizada, dentre outras formas, também por meio da literatura, por meio de um novo olhar, olhar este que abarcou 
inúmeras revoluções estéticas, as quais poderiam apenas ser expressas através da paródia e da linguagem poética - recursos, ambos, transgressores das formas tradicionais.

A fim de revolucionar a sociedade, os escritores lançaram mão, então, da revolução estilística, a qual tencionou também derrubar as barreiras ditatoriais da linguagem estabelecidas pelo discurso organizador e ordenador da prosa, utilizando a prosa-poética como procedimento transgressor. E, juntamente às inúmeras mudanças estruturais na sociedade, ocorreram, acima de tudo, as mudanças nas mentalidades: "A revolução sonhada, aquela que muda consciências, tem os seus soldados nos escritores, não no exército armado" (SIMÕES, 1997, p.212).

Tais revoluções formais caracterizam, de acordo com Miguel Real, esta geração do "novo romance esteticista e desconstrucionista" (REAL, 2012, p.95), cujas produções romanescas se iniciaram entre as décadas de 1960 e 1970, e que apresentam

uma autêntica revolução formal e ideológica, contestando, igualmente, as categorias tradicionais da composição clássica do romance, subvertendo as unidades de tempo e de espaço, autonomizando a categoria de tempo da de espaço e revolucionando a sinalética morfológica habitual, substituindo, não raro, a ação e a intriga pela reflexão subjetiva e ensaística do narrador ou das personagens. (REAL, 2012, p.95)

Realizando uma completa desconstrução das categorias tradicionais do romance, as produções desta geração ilustram a deterioração e desmantelamento das estruturas do sistema estatal salazarista e a relativização dos conceitos de verdade e mentira, obtendo-se, como resultado, os jogos formais complementares - recriar, criar, recrear - a fim de levar o leitor a aceitar o pacto com a ficção. A busca que embasa essa narrativa é alimentada pela dúvida, a qual se constitui como a “(...) única via capaz de promover a conjunção de distração (recrear) e intervenção (re-criar), ludicidade e lucidez” (DIAS, 2011, p.101), girando em um circuito suspenso das falas, impossibilidades e tensões, o que conduziu à subversão da estrutura tradicionalista do romance e direcionou-o à sua impossibilidade. A narrativa tradicional, subvertida por meio de

a. ausência de um narrador fixo e majestático, substituído por um processo narrativo de construção testemunhal dos factos; b. ausência de factos absolutos, totalmente conhecidos, substituídos pelo perspectivismo narrativo; c. a introdução do parênteses (...), com abrupta interrupção da narrativa, para apresentar um facto de memória, indiciando ser a narrativa mais composta de anotações, observações, 
versões, perspectivas, do que de factos esclarecidos. (REAL, 2012, p.9798).

Igualmente constitui-se transformada em sua sinalética e sintaxe, fazendo com que o leitor necessitasse alterar a sequenciação na leitura das frases, apreendendo-as muito mais como um fluxo musical e uma cadência instintual de ritmo, refletindo a projeção da consciência das personagens. Esta nova estilística, que subverteu tanto a estrutura linguística quanto a estrutura tradicional do romance, tencionou, da mesma forma, espelhar a condição humana na contemporaneidade, entre sentimentos de incompletude e de vida fragmentada. Segundo Real,

a desestruturação e desconstrução de todos os fundamentos ontológicos e civilizacionais presentes classicamente tanto na sociedade quanto no romance. A tradicional narração de uma história alimentada cronologicamente com princípio, meio e fim, desaparece do romance narram-se episódios soltos, impressões, iluminações, acontecimentos avulsos, apresentados caoticamente, que o leitor deverá reconstruir. (REAL, 2012, p.102)

Tendo acompanhado, destarte, os movimentos políticos e sociais das décadas de 1960 e 1970, combatido o regime ditatorial salazarista e reinventado os mitos do povo português, a literatura contemporânea propiciou uma violentíssima ruptura na trama narrativa, refletindo a ruptura na trama histórico-social de Portugal, e deixando de herança para a próxima geração de escritores, em suma,

1. autonomia semântica e sintática do texto face à realidade exterior; 2. incorporação da realidade exterior na lógica do sujeito - memória, imaginação, pulsões plurais do sujeito prevalecem sobre a lógica da realidade exterior, forçando esta a adaptar-se ao texto; 3. o texto é dominado por um tempo interior - cruzamento de três dimensões e/ou fragmentações do tempo em instantes eternos; 4. a realidade torna-se inspiradora do texto, mas não domina este; 5. a estrutura sintática do texto reflete um pensamento anti-categorial, segundo uma nova lógica de modalidade e perspectivas ou hipóteses; 6 . não existe um eu fixo (sujeito) e não existe um objeto fixo e permanente senão ilusoriamente. (REAL, 2012, p.109)

A Geração das décadas de 1980-1990, da qual Inês Pedrosa é partícipe, além de haver herdando todas as subversões estilísticas daquela que a precedeu, retomou o Realismo em sua escritura textual por meio das temáticas históricas, marcando suas produções literárias com o estilo narrativo desconstrucionista. 


\section{A Voz de Inês Pedrosa}

Inês Pedrosa, mesmo tendo nascido na década de 1960, traz em seus escritos os questionamentos e apontamentos históricos característicos da literatura portuguesa produzida desde A Sibila, de Agustina Bessa-Luis, indicando as rupturas acontecidas na narrativa, na família, nas subjetividades individuais e no regime político de Portugal, anteriores e posteriores à Revolução dos Cravos. A substituição do narrador demiúrgico do romance, a pluralização e autorreferencialidade da vOz narrativa num intenso jogo metalinguístico estão presentes em todas as suas obras. Bem como as metáforas da transformação social e cultural ocorridas no Portugal pós-queda da ditadura salazarista, cujos prolongamentos abrangem a consciência do sujeito a respeito de si mesmo e do outro, em um mundo desumanizado pela contemporaneidade e pela globalização.

Em sendo partícipe da geração desconstrucionista, a produção pedrosina apresenta, em comparação às obras de seus predecessores, uma profunda transformação da lógica interna de seus romances, a qual, marcada por uma ordem não linear e por múltiplos cruzamentos de perspectivas narrativas, prima por uma ordem aparentemente desconexa e incoerente, comportando saltos que subvertem o tempo-espaço interno ao texto.

O autoquestionamento das personagens principais em relação à sua existência espelha-se nesta elaboração marcada pela desconstrução da escrita, reafirmada pela profunda solidão existencial das personagens. Assim, a palavra poética, único procedimento formal capaz de expressar tais vazios e questionamentos humanos, particulariza a escrita pedrosina e estabelece seu lugar na literatura em revolução - já que a transgressão estilística, preconizada desde meados dos anos 1950 em Portugal, incluiu também derrubar as fronteiras ditatoriais da linguagem definidas pelo discurso organizador e ordenador da prosa.

Associada aos questionamentos a respeito das mudanças estruturais na sociedade, as obras de Inês Pedrosa também colocam em pauta a mudança das mentalidades, a partir do momento em que sua escrita estabelece o contraponto da voz da autoria feminina - a voz da diferença -, interpelando o discurso ditatorial patriarcal salazarista que se perpetua em Portugal, travestido de androcentrismo. À semelhança de suas antecessoras, utiliza, em algumas de suas composições, a escrita feminina a fim de construir narrativas que espelhem o subjetivismo fragmentado do indivíduo contemporâneo.

Inês Pedrosa, por meio de sua produção romanesca, questiona constantemente as transformações sociais ocorridas no último século, mas, acima de tudo, confronta seus 
leitores, expondo as incertezas de um mundo em fragmentos, de seres humanos com identidades cindidas, de relacionamentos sem afeto. Utilizando-se da escrita literária, empenha-se na tentativa de expor as incoerências e os anacronismos de um mundo improvável e de gerações de indivíduos sem consciência política e, igualmente, sem propósitos pessoais e coletivos. Este despropósito, enredado em estereótipos e crenças sociais engendradas em pontos de vista obsoletos, constitui o enredo da obra romanesca pedrosina, invariavelmente decomposto por meio da desconstrução das personagens e da narrativa em si, a fim de empreender uma busca absurda nesta contemporaneidade sem expectativas: a busca pela identidade, pela humanidade e pelo relacionar-se. Engendrando, da mesma maneira, as incertezas a respeito do lugar que a própria literatura ocupa enquanto representação da vida nesta sociedade despedaçada, a obra romanesca de Inês Pedrosa pontua, em cada um de seus elementos narrativos, a desconstrução, não apenas da vida, mas também da arte contemporânea.

Nascida em Coimbra, Portugal, no ano de 1962, Inês Pedrosa licenciou-se em Comunicação Social pela Faculdade de Ciências Sociais e Humanas da Universidade Nova de Lisboa em 1984 e, atualmente, frequenta o curso de doutorado em Línguas, Literaturas e Culturas desta mesma universidade.

Em janeiro de 1983, iniciou sua carreira como cronista, tendo publicado suas crônicas em diversos jornais, incluindo o Jornal de Letras, Artes e Ideias e O Expresso. A compilação de suas crônicas relacionadas à condição da mulher na sociedade portuguesa deu origem ao livro Crónica Feminina, publicado em 2005.

Sua primeira obra romanesca, A instrução dos amantes, foi publicada em 1992 e, em 1997, Nas tuas mãos, romance que recebeu o Prémio Máxima de Literatura, prêmio este que voltou a receber, em 2010, com a obra Os intimos. Além de romances, Inês Pedrosa também publicou 20 Mulheres para o século XX, ensaio que teve início em um projeto para o semanário $O$ Expresso. Compõe-se de um conjunto de biografias de mulheres marcantes do Século XX, dentre as quais figuram Simone de Beauvoir, Agustina Bessa-Luís, Coco Chanel, Frida Kahlo, Lou Andreas Salomé, Virginia Woolf, entre outras. Embora Fica comigo esta noite, livro publicado em 2003, seja uma reunião de contos anteriormente escritos de maneira esparsa para jornais e revistas, constitui-se em uma obra permeada pelas vozes femininas da contemporaneidade, que questionam os homens modernos e suas identidades e desejos. 
Assume-se como corpus para este estudo o romance Fazes-me falta, o qual, publicado em 2002, e analisado em seus aspectos formais, suas representações e metáforas, evidencia a importância da criação literária de Inês Pedrosa para o panorama da Literatura Portuguesa Contemporânea.

A estrutura narrativa da obra apresenta-se em dois blocos de falas, uma em voz feminina e outra, masculina, assemelhando-se à A paixão (1965), de Almeida Faria ${ }^{3}$, como Gomes assinala: "Ao dividir a narrativa em blocos, ou fragmentos, cada um deles pertinente a uma personagem, (A paixão) parece acentuar essa ideia de confinamento do Homem" (1993, p.92). Ao mesmo tempo, os questionamentos relativos ao lugar da mulher e do homem na sociedade contemporânea portuguesa, como resultados e reflexos de décadas de repressão e condicionamento patriarcais impostos pelo programa de governo de Oliveira Salazar, e a tentativa, por meio da escrita literária, de descolonizar a mulher, nas palavras de Simone de Beauvoir, são abordados em Faz̧es-me falta, como também o são em A sibila (1954) de Agustina Bessa-Luis; Novas cartas portuguesas (1972), de Maria Teresa Horta, Maria Isabel Barreno e Maria Velho da Costa; O dia dos prodígios (1979), de Lídia Jorge; e Paisagem com mulher e mar ao fundo (1982), de Teolinda Gersão.

Da mesma maneira que ocorre em inúmeras obras portuguesas contemporâneas, a narrativa de Faz̧es-me falta se dá de forma caótica e não-linear, em uma espécie de puzzle (GOMES, 1993, p.120), dada a mistura de discursos diretos e indiretos, a modificação na noção tradicional de narrador - substituído, este, por duas vozes que não se comunicam diretamente, fazendo com que o leitor (outra marca contemporânea) tenha uma participação ativa na construção de sentido da obra - e a subversão da sinalética e da estrutura das frases. Associada a este panorama está a utilização da prosa-poética, gênero linguístico que abarca em sua dinâmica as subversões empreendidas pelos escritores contemporâneos, além de também validar a luta ideológica contra a opressão ditatorial da linguagem considerada convencional - a prosa linear, organizadora e normatizadora das relações sociais.

\footnotetext{
3 A obra de Almeida Faria, entretanto, mesmo tendo sido construída em diversos blocos de falas à semelhança do corpus em estudo, alterna não apenas as vozes de duas personagens, mas contempla vozes diversas pertencentes à família protagonista e seus agregados.
} 


\section{O (des)fazer literário: A (des)tessitura da mulher e da narrativa em Fazes-me Falta}

O termo escrita feminina - enquanto constructo teórico literário-psicanalítico, como explicitado a seguir -, foi desenvolvido por Lúcia Castello Branco, psicanalista e crítica literária, que, no intuito de estabelecer as bases para a fundamentação do termo, postulou que

não se trata de detectar uma anatomia do texto, mas de examinar uma configuração discursiva específica - entendida, a partir de uma série de correlações, como feminina, mas que afinal pode ser concebida tanto por homens quanto por mulheres. (BRANCO, 1990, p.12-13)

Abarcando as contribuições da psicanálise, ampliando-se aos percursos teóricos de Kristeva, Derrida, Deleuze e Guattari e sobretudo Barthes e Lacan, a escrita feminina tem como objetivo pontual a análise do texto literário. Branco afirma que ao estudo dessa escrita pouco importa o sexo biológico do autor do texto (e, em decorrência, o sexo do texto) mas como sua trama se constrói, quais especificidades discursivas podem nele ser pontuadas, a fim de realizar um traçado - uma cartografia:

não propriamente um mergulho nas profundezas do texto, mas um passeio por suas superfícies, um mapeamento, uma cartografia. Nessa viagem se pretende assinalar a dimensão temporal descontínua da memória, as terras da literatura, (...), a materialidade da letra feminina, os entrecruzamentos entre a memória e a ficção. (BRANCO, 1990, p.16-17)

O constructo da escrita feminina não ocorre, destarte, tão somente por meio de semelhanças temáticas, pertinentes ao enunciado, mas, antes, através de processos discursivos nos quais "a linguagem é sempre levada ao paroxismo de seus próprios limites" (BRANCO, 1990, p.16). Construída por uma linguagem marcada pela prosa-poética, entremeada por metáforas e apresentando marcas de ritmo e cadência específicas, essa escrita invariavelmente articula-se a partir de uma linguagem que produz um texto de gozo, na acepção que Barthes confere a esse termo:

Texto de fruição: aquele que põe em estado de perda, aquele que desconforta (...), faz vacilar as bases históricas, culturais, psicológicas do leitor, a consistência de seus gostos, de seus valores e de suas lembranças, faz entrar em crise sua relação com a linguagem. (BARTHES, 2013, p. 20-21)

A fim de compreender a escrita feminina enquanto texto de gozo, faz-se necessário comparar a sua composição à tessitura de uma renda - cujas linhas tanto constituem quanto margeiam os buracos, as fendas, os vazios, mas não os preenchem: "A lacuna 


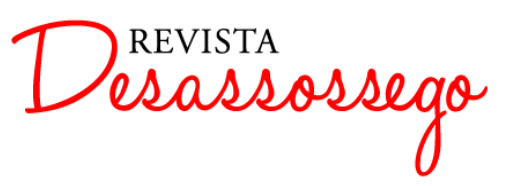

desses textos (...) é um elemento estruturante: é em torno do vazio, do buraco, da falta, que a escrita feminina se constrói”" (BRANCO, 1991, p.57). Em sendo tessitura, enreda o leitor, por meio de uma linguagem margeante, em sua malha, em sua rede de sentidos; e, em sendo margem, lança a própria narrativa ao precipício, à beira da morte, visto que retira desta todas as certezas e limites, levando-a a extremos de sentidos.

O texto dessa maneira produzido é tecido e destecido às vistas do leitor, oferecendo-lhe mais dúvidas do que certezas, mais ausência do que presença e desafiando os limites linguísticos tradicionais. Assim configurada, uma narrativa desta forma produzida invariavelmente espelha e é espelhada por um enredo fragmentado, em uma intermitente tensão entre os polos da continuidade e da descontinuidade (do tecer e do destecer): buscando traçar uma linha narrativa contínua, delineia uma trama intervalar, cujos sujeitos narrativos oscilam entre a presença e a total desconstrução.

Produzindo textos que jamais se permitem desvendar por completo e que concedem à lacuna e à falta um lugar privilegiado em sua tessitura, a escrita feminina faz uso de uma composição cujo elemento primordial é a morte - primordialmente enquanto fator de (de)composição da trama linguística, pois que tal figuração "exibe a perda, por apresentar o vazio sem buscar obturá-lo e por fazer desse vazio e dessa perda os motores de produção de sentido e de palavras" (BRANCO, 1991, p.36). Escrita sempre em construção, em movimento, em processo, sempre inacabada, a abolição dos limites linguísticos e a continuidade-descontinuidade narrativa são plenamente refletidas pela e na prosa poética e a linguagem erótico-amorosa, cujas funções sintáticas e semânticas apresentam-se subvertidas em prol do sentido, do ritmo, da cadência e da pulsação textuais. Corroborando esta concepção, Branco expõe que “o gozo está contido nesse movimento em direção à morte: das vibrações, palpitações e suspiros, que sugerem uma atmosfera evidentemente erótica da linguagem" (1991, p.53), ao que Barthes (2013) complementa ao salientar que o texto traga - e seduz, violentamente - o leitor para o seu íntimo, ao utilizarse dessa constituição formal.

Em Faz̧es-me falta, Inês Pedrosa encena uma narrativa de vínculos e separações que, entre o amor, a amizade e o desejo, expõe os afetos (in)existentes entre uma mulher morta - a personagem feminina - e um homem vivo - a personagem masculina. Durante o velório do corpo dela, ambos empreendem uma jornada elaborada em monólogos, permeados de desespero e pranto, na tentativa de compreender a ausência definitiva, a 
partir da qual o enredo se enuncia no romance: a ausência dos afetos e vínculos e, principalmente, a ausência do corpo da personagem feminina.

A reinvenção da forma de narrar singulariza a Literatura Contemporânea Portuguesa, transformando, consequentemente, a linearidade da narrativa e a tessitura da linguagem romanesca, essa marcada pela poeticidade, pelo fluxo de consciência e pela análise do mundo, bem como pela autorreflexão em relação à própria estrutura e forma literárias. Esses elementos, em conjunto, caracterizam o discurso caótico da Escrita Feminina, estruturante da obra Faz̧es-me falta, por meio de uma composição que (des)constrói a narrativa.

O aparente caos narrativo, em puzzle, é reforçado pelo fato de a obra ser fundada na poeticidade, constituindo um texto em fragmentação, em ruptura e descontinuidade temporais, marcando a completa destruição do enredo. A narrativa em questão enuncia uma fala subreptícia, resistente e sempre dissidente, uma poética da perda e da morte, da falta irremediável e do indizível - a linguagem da escrita feminina, a qual se anuncia traçada e tecida, sobretudo, "na perda e na lacuna, (compondo) um viscoso limbo discursivo, onde as palavras explodem, implodem e nada dizem, além desse impossível de dizer" (BRANCO, 1990, p.341-342).

A linguagem poética, lírica, está presente em todo o texto, construindo uma forte imagética permeada de metáforas, visto ser esta a única tessitura possível para expressar os sentimentos das vozes narrativas, pois que as palavras cotidianas, a prosa linear e organizadora, não dão conta de manifestar a ausência e as lacunas constitutivas do relacionamento entre as personagens feminina e masculina de Fazes-me falta as quais, já em suas primeiras falas, exprimem poeticamente a morte e consequente sentimento de ausência:

[Ela] Agora que saí do corpo que fui - para me tornar pólen, poeira nos teus olhos, pura imaginação de mim - imagino-o melhor ainda, ébrio de luz, lúcido, encandeado por um Lúcifer oculto e criador incrustado no seu próprio ser, em estado de paixão com a história desencadeada pela sua omnipotente solidão. E balouço no Seu sorriso outra vez, a vez definitiva porque o meu corpo está lá em baixo, num caixão, contemplado e lembrado e chorado pela última vez. (PEDROSA, 2003, p.10)

Fazes-me falta, apresentando-se tanto enraizado na prosa poética quanto no erotismo, divergente do pensamento linear-prosaico e que se abeira, como a própria poesia, dos limites da linguagem, em um movimento incessante de palavras que exibem nuances e 
vacuidades. "A poesia é feita de palavras enlaçadas que emitem reflexos, vislumbres e nuances (...), e nos fazem ouvir o inaudito e ver o imperceptível”, ensina Paz (1994, p.11) e, ao proferir o imperceptível, a palavra poética, da mesma forma, apresenta uma "festa de linguagem, em seu espetáculo de perda e de desordem, de loucura e de siderações do sujeito" (BRANCO, 1990, p.434).

No romance pedrosino em estudo, a escrita feminina se constitui, na verdade, em uma desescrita, em uma destessitura da narrativa, explícita nas lacunas e nos abismos da linguagem utilizada, à semelhança de todo processo poético que, levado aos seus limites, aproxima-se desse lugar. O destecer narrativo é pontuado logo no primeiro monólogo da personagem masculina que, ao definir o que o unia à personagem feminina, expressa: " $\mathrm{O}$ que existia, existe, entre nós, é uma ciência do desaparecimento. Comecei a desaparecer no dia em que os meus olhos se afundaram nos teus. Agora que os teus olhos se fecharam, sei que não voltarás a devolver-me os meus.” (PEDROSA, 2003, p.12). Uma ciência do desaparecimento igualmente ocorre com a própria composição, ao longo da narrativa.

As inúmeras alusões às imagens da personagem feminina - morta - agregam-se à ideia da fragmentação, a qual perpassa toda a narrativa, relacionada tanto às personagens e ao enredo, quanto à tessitura composicional; marcada pela força lírica, como também pela escrita feminina que, em Faz̧es-me falta, tece e destece a morte - morte essa não apenas da personagem feminina, mas de todo o corpo textual da obra -, a narração do corpo morto da protagonista sugere a metáfora central, metáfora que institui a cadeia de camadas textuais estabelecidas por essa morte alegórica. Morrendo, a personagem feminina revela o vazio da vida, do saber e da contemporaneidade, visto que principia uma reflexão a respeito da sua (in)existência e, assim, expõe a incompletude que a mulher contemporânea vivencia na sociedade atual.

Partindo de um corpo feminino morto, mas presente do início ao fim da narrativa, instaura-se uma lógica outra: a lógica do corpo impossível e que, excedendo os limites das possibilidades, constrói um texto urdido nas perdas e lacunas da morte. Ao obedecer a esse processo morrente, ou à lógica do gozo, como observa Roland Barthes (2013), constitui-se uma história que se tece à margem, sem uma orientação espaço-temporal definida, pois que os sujeitos narradores falam de diferentes lugares e seus discursos ora se confundem, ora divergem, deflagrando uma verdade incompleta, que nega a si mesma e se questiona, pois que baseada em afetos e não em fatos. Os discursos, fragmentários, de indivíduos fragmentados, habitados por desejos diversos, subvertem a unidade narrativa, construindo 
um puzzle não apenas da narrativa, como também do corpo da personagem. Um corpo textual despedaçado, esfacelado, expõe uma incompletude intransponível, que, carregada de erotismo, leva ao gozo no corpo da mulher morta.

Romance representativo da contemporaneidade, Fazes-me falta, por meio de sua linguagem e técnica narrativas, desconstrói assim as noções tanto de narrador quanto de autor, e subverte o conceito de verdade, consequência da fragmentação que ocorre tanto nas identidades humanas na sociedade contemporânea quanto na materialidade textual, a qual se faz presente no corpus do texto por meio das metáforas da morte corporal e na incomunicabilidade entre as personagens feminina e masculina, retratando a ordem do nãosaber, da não-nomeação e da morte. Sendo a mulher e a narrativa elementos associados nesta obra pedrosina de forma singular, o corpo morto e o corpus textual sofrem simultaneamente um processo de decomposição, que se acompanha, por meio da repetida referência às inúmeras faltas e ausências, durante a narrativa. Esta se constrói e se desconstrói como o corpo feminino da protagonista, que também progressivamente se decompõe, em suas lacunas e fendas abertas, revelando o vazio e o nada:

[Ele] Tu esfumaste-te, já não posso ficcionar-te. (...) Talvez pudesse partir desta névoa para um ensaio sobre a fragilidade da vida e a cegueira das ambições - mas isso não seríamos nós. Além de que herdei de ti um puro prazer da vida que se esgota numa só página. (PEDROSA, 2003, p.143-144)

O corpo feminino, lugar de um erotismo excessivo, portanto transgressor, abissal e mortífero, como postulado tanto por Roland Barthes quanto por Georges Bataille, conduz a personagem masculina à morte. Uma experiência de ruptura, uma violência e uma violação que, no entanto, permite o gozo do conhecimento. Destarte, no presente romance pedrosino, a alusão à fusão entre o corpo da mulher e o corpo da narrativa se dá desde o início, no momento no qual a personagem masculina coloca: "Entraste na narrativa" (PEDROSA, 2003, p.13); de fato, deste ponto em diante, a morte e a destruição, a desconstrução e decomposição passam a referir-se tanto à personagem feminina quanto à narrativa, expondo sua comunhão.

Por nunca poder-se dizer tudo a respeito do não-todo, já que a mulher - e a narrativa - é morta, definida por falas alheias, tecida por fios em desconstrução, ao romance, que se inicia e termina na imagem dela, afigura-se a impossibilidade de amenizar o vazio da existência da personagem masculina, que se mantém na incomunicabilidade; 
nada pode-se saber sobre ela, pois que não se enuncia, nem mesmo se nomeia, revelando em Fažes-me falta a perpetuidade do não-saber, da incomunicabilidade e da ausência. Constituindo-se como uma narrativa de morte, a obra afigura-se, em verdade, em uma narrativa morta, tão morta quanto a personagem feminina - uma mulher-narrativa morta. As mesmas metáforas, em um discurso lacunar e cindido, (de)composto por silêncios e ausências, abre fendas em ambos os corpos, os quais relatam o nada em torno do mesmo - a fragmentação e a incompletude:

[Ela] E parecia-me que a graça da existência consistia em procurar vozes na noite - uma noite cuja cauda se arrasta pelo fundo do mar e pelo interior da terra, uma noite que o vapor branco do sol apenas abre um pouco mais. Assim me apaixonei pelos livros - pela noite que neles nos invade, quando os abrimos, pela noite que neles nos resiste, depois de lidos, relidos e fechados. Pela noite que prossegue, incansável, entre as palavras, as palavras sem dono, escritas da ausência para a ausência. (PEDROSA, 2003, p.97)

A noite. $O$ negro. $O$ vazio. Livros escritos da ausência para a ausência, os quais apresentam uma personagem ausente que, em uma única imagem, reúne todas as mulheres importantes da vida de seu amigo, em uma alegoria ao feminino arquetípico, por isso nãonomeado e não-representado, mas onisciente - a mulher (narrativa) abre o discurso, ferido, perante um homem perplexo, culpado e viúvo, repleto de interrogações mas que obtém como retorno apenas o silêncio: ela não o ouve em seu desespero impotente, e ele não a ouve em sua saudade. Vagando entre o velório, o enterro e a solidão, a personagem masculina, por meio de seus monólogos, tenta, na verdade, recompor a imagem desta mulher, remontar o puzzle de seu corpo fragmentado.

Mais do que uma relação simbólica entre a personagem feminina e a narrativa, todavia, existe uma congruência, uma relação de identidade entre uma e outra, uma equivalência entre o corpo da personagem feminina e o corpus narrativo, inclusive no que tange a crítica social explicitada em Fažes-me falta, relativa ao poder e ao sistema. Os embates a respeito da ausência de ética nas relações, da falta de assistência social à criança em risco, do estado de agressão constante às mulheres são temas não apenas debatidos no romance, mas também postos em carne viva na representação de morte da personagem feminina, presentificando a situação de apodrecimento do status quo vigente na sociedade contemporânea. Tal fato pode ser observado na seguinte fala da personagem feminina, tecendo em sua posição de mulher-narrativa: 
A surdez para o sofrimento dos acasos permanece no centro da nossa tão sofisticada ciência animal. Cada lágrima que choras por mim, fechado na tua casa de silêncio, representa um dia a menos na vida da próxima criança que vai morrer lentamente, na requintada Europa, sem ter sequer conhecido os prazeres da vida. (...) Mas tu, porque caminhas para a morte e agradeces à ordem natural das coisas cada um dos teus dias de sol, dirás que a culpa é da organização da sociedade. Dormirás tranquilo, aninhado no conforto da falta que eu te faço. Morrendo devagar, partícula a partícula. Ouço o som da morte na tua pele, livro que se encarquilha na câmara húmida do tempo. Há quanto tempo não te arde o coração? (PEDROSA, 2003, p.54-55)

Ao mesmo tempo, a personagem masculina é quem inaugura o desejo de destruição e da desconstrução da narrativa, ao assinalar o começo da morte de sua amiga a partir do momento em que ela iniciou sua carreira política. Assim, este é o leitmotiv da decadência e da morte, apontado no romance: a política. O sistema. O cânone. Contudo, é também a personagem masculina quem tenta manter viva a mulher-narrativa, colocando, inclusive, ao lado de sua cama um retrato dela - imagem de uma cicatriz, algo que ficará sobre a pele eternamente, até a morte. A morte dele. Ou do machismo em Portugal. Talvez, da literatura canônica androcêntrica.

Em Fazes-me falta, tudo falta: falta o corpo vivo, falta a memória exata, falta dizer, o que para as personagens (e para a narrativa) é o mesmo que a agonia da morte, a solidão, a ausência, fatores que instauram as brechas e fendas, em um discurso feminino de jogos, apresentações e ocultamentos, inscrevendo assim o gozo no texto:

[Ele] Eras tão obsessiva em tudo. Queria roubar-te a obsessão, ter outra vez os teus vinte anos. (...) A sabedoria do gozo, avessa à ciência do prazer. A felicidade esgotava-te, o sofrimento exaltava-te, nada era fácil para ti. (...) É por isso que não perdoo a tua morte. Crava-se-me nos ossos. Sou a tua morte, para que tu vivas ainda. (...) O que viverás de ti quando eu morrer? (PEDROSA, 2003, p.106)

O romance, estruturando-se destarte à sombra do corpo morto da mulhernarrativa, explicita a não-existência do real, do tempo e do sujeito; corpo transformado em escrita descontínua, como a imobilidade do corpo morto, este discurso feminino interrompido e lacunar, sem nome próprio, apresenta-se constituído por uma precária ancoragem, transformando-se em um náufrago de seu próprio discurso. Tessitura em renda, a escrita feminina em Fazes-me falta "desobedece à lógica cartesiana, desordenada, repleta de lapsos evidentes, de um ritmo cíclico e entrecortado" (BRANCO, 1990, p.217) e deixa à mostra todas as faltas da composição, pois aquilo que falta às personagens é igualmente aquilo que falta ao texto: a mulher-narrativa. 


\section{Considerações Finais}

Na obra Faz̨es-me falta, Inês Pedrosa metaforiza o corpo morto, desconstruído, retaliado, da personagem-narradora a fim de fazer imergir nessa fragmentação o discurso literário, o qual, por apresentar-se construído por meias-palavras e meias-verdades, pulveriza a imagem da mulher-narrativa e constrói um texto em eterna busca. E, destarte, é que, tecida pela escrita feminina, essa narrativa tanatológica e melancólica questiona a inteireza e a completude - e a existência - da mulher contemporânea, e aponta a deterioração do próprio discurso literário, articulando uma ressignificação em relação ao poder desse mesmo discurso, pois que essa escrita engendra uma narrativa questionadora do paradigma oficial por abeirar dos abismos da linguagem. Ao redor dessa ausência de sentidos silenciosa, é que a mulher-narrativa se (des)constrói, compondo um texto fraturado, configurando sua completa incompletude.

A mulher-narrativa, morta, revela assim o vazio insuportável que subjaz à hipocrisia social de sua cultura; o seu corpo morto, exposto no velório, aberto à visitação de seus contemporâneos e supostos amigos em vida, denuncia a ausência de todos e a sua própria, em relação ao contato humano. Em vida, a ordem da transgressão a marcou, uma presença subversiva em uma sociedade machista, pós-ditatorial - uma mulher que ousou romper a ordem, trazendo uma voz que possibilitou uma transformação nas relações de amizade entre uma mulher e um homem, tornando-a profunda e real, assunto que tanta polêmica gera em contextos machistas. Tal fraternidade, sem a marca da sedução e da sexualidade, afigura-se igualmente como uma marca de transgressão narrativa, posto que a literatura portuguesa contemporânea de autoria feminina, principalmente, possui a marca subversiva das vozes que exigem reconhecimento social, em igualdade de gêneros, em contraponto ao absurdo da vida, das certezas, das supostas verdades.

\section{REFERÊNCIAS}

BARTHES, Roland. O praz̧er do texto. São Paulo: Perspectiva, 2013.

BATAILLE, Georges. O erotismo. Trad. Fernando Scheibe. Belo Horizonte: Autêntica Editora, 2014.

BRANCO, Lúcia Castello. A traição de Penélope: Uma leitura da escrita feminina da memória. Tese de Doutorado - UFMG, Belo Horizonte, 1990. O que é escrita feminina. São Paulo: Brasiliense, 1991. 
DIAS, Maria Heloísa Martins. "O mestre, de Ana Hatherly: Uma insólita aprendizagem”. São José do Rio Preto, UNESP: Revista Angulo, 125, Abr.-Set., 2011. p.98-105. Disponível em: http://www.fatea.br/seer/index.php/angulo/article/viewFile/801/564.

GOMES, Álvaro Cardoso. A voz itinerante. São Paulo: Edusp, 1993.

PEDROSA, Inês. Fažes-me falta. São Paulo: Planeta, 2003.

REAL, Miguel. O romance português contemporâneo: 1950-2010. Lisboa: Editorial Caminho, 2012.

SIMÕES, Maria de Lourdes N. "Para não dizer que não falei dos cravos". IN: As rąõos do imaginário - Comunicar em tempos de revolução. Salvador: UESC, 1997.

Data de recebimento: 22/04/2017

Data de aprovação: 28/12/2017 